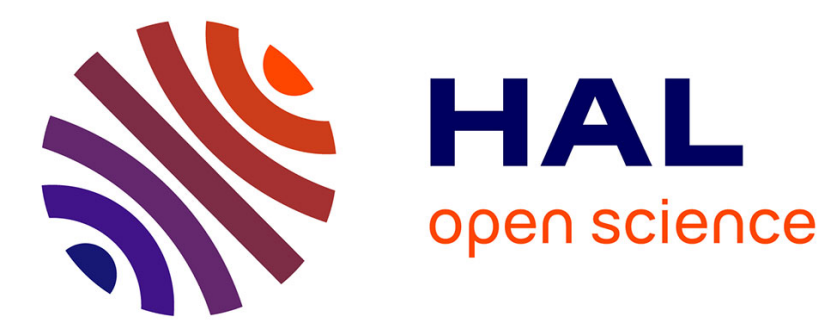

\title{
Analysing constraints to improve conservation decision-making: a theoretical framework and its application to the Northern Vosges, France
}

Anaï Mangos, Juliette Rouchier, Yves Meinard

\section{- To cite this version:}

Anaï Mangos, Juliette Rouchier, Yves Meinard. Analysing constraints to improve conservation decision-making: a theoretical framework and its application to the Northern Vosges, France. Environmental Conservation, 2021, 48 (3), pp.174-181. 10.1017/S0376892921000175 . hal-03482417

\section{HAL Id: hal-03482417 \\ https://hal.science/hal-03482417}

Submitted on 17 Dec 2021

HAL is a multi-disciplinary open access archive for the deposit and dissemination of scientific research documents, whether they are published or not. The documents may come from teaching and research institutions in France or abroad, or from public or private research centers.
L'archive ouverte pluridisciplinaire HAL, est destinée au dépôt et à la diffusion de documents scientifiques de niveau recherche, publiés ou non, émanant des établissements d'enseignement et de recherche français ou étrangers, des laboratoires publics ou privés. 
1 Analyzing constraints to improve conservation decision making: a theoretical framework and its application to the Northern Vosges, France

Anaï MANGOS ${ }^{1}$, Juliette ROUCHIER ${ }^{1}$, Yves MEINARD ${ }^{1, \#}$

${ }^{1}$ Université Paris-Dauphine, Paris Sciences et Lettres Research University, CNRS, UMR [7243], LAMSADE, Place Lattre de Tassigny, 75016, Paris, France

${ }^{\#}$ Corresponding author: yves.meinard@1amsade.dauphine.fr

Acknowledgements - This article is based on a work financed through the ECOSERV

INTERREG project. We thank the member of the policy analytics research team for their support, comments, and criticisms. We also thank two anonymous reviewers and the journal's Editors for their important criticisms and suggestions.

Summary - Key to bridging knowing-doing gaps is analysis of the constraints binding interactions between decision makers and conservation biologists to clarify the problem they address. We apply this analysis to decision situations in the Northern Vosges (France), which illustrate three kinds of constraints - governance, framework, and initiative. We explore how conservation biologists can mitigate constraints so as to foster more ambitious conservation actions in each case. The first case explores attempts at reintroducing the lynx (Lynx lynx). In this case, we show that governance plays a key role, in the sense that conservation actions should focus on improving the acceptability of reintroductions to key stakeholders. The second case refers to water monitoring schemes. Here we show that framing is the dominant constraint. 
apparatus. The last case study, fish stock protection, is constrained by initiative. Here, decision makers have too much leverage to implement solutions they favor, even if they are not the best options in conservation terms. Exploring how our framework relates to the existing literature allows us to highlight its usefulness to rationalize conservation problem framing and to strengthen the ambition of conservation actions.

Keywords - conservation decision, decision support, environmental policy, governance, knowing-doing gaps, decision process

\section{Introduction}

Following seminal calls for evidence-based conservation (Sutherland et al. 2004) and conservation policy evaluation (Ferraro and Pattanayak 2006), numerous articles have recently championed bridging knowing-doing gaps in conservation (Arlettaz and Mathevet 2010; Beier et al. 2017; Jeanmougin et al.2017, Matzek et al., 2014; Schwartz et al. 2018, Jarić et al. 2019, Knight et al. 2008; Sunderland et al. 2009; Biggs et al. 2011; Game et al. 2015). When conservation biologists, experts or consultants (hereafter, 'CBs') interact with decision makers (hereafter, 'DMs') facing a problem with conservation bearings, they can have the naïve view that bridging knowing-doing gaps simply means solving the problem by providing a scientifically robust recommendation.

However, conservation actions often involve series of complex decisions made by human beings in complex social contexts. Insights from decision sciences can help in forming a more informed picture of $\mathrm{CB} / \mathrm{DM}$ interactions, useful to empower attempts at bridging knowingdoing gaps. Tsoukiàs (2007) synthesises these insights by conceptualizing decision support processes (i.e., processes where a DM and an analyst (in our case: a CB) interact to address the 
DM's problem) as articulated around: a representation of actors and their roles; a problem formulation, mentioning anticipations of what actors expect; and an evaluation tool.

The lesson from Tsoukias (2007) is that the naïve picture above should be overcome by taking into account actors, expectations and tools, but this does not explain the precise role of these elements in shaping the problem and $\mathrm{CB} / \mathrm{DM}$ interactions. Here, we propose to take advantage of a framework developed by Meinard and Tsoukiàs (2019) to overcome this limitation. We then put this framework to the test in a series of case studies in the Northern Vosges Natural Park (France).

\section{Methods}

\subsection{Theoretical framework}

Meinard and Tsoukiàs (2019) argue that the actors, expectations and tools mentioned by Tsoukias (2007) are the building blocks of 'constraints' binding CB/DM interactions. These constraints mold the problem that the process addresses.

Typically, most decision processes herald a formulation of the problem they allegedly address. This formulation is used in administrative procedures such as public procurements, in official communications with journalists or the larger public, or when organizing events such as internal meetings. However, the constraints binding $\mathrm{CB} / \mathrm{DM}$ interactions can make it impossible to address this problem. The latter then becomes what we propose to call a 'proto-problem', heralded but not addressed in practice, as the process in fact tackles a problem that can be operationally addressed, which we propose to call the 'constrained problem'.

Meinard and Tsoukiàs (2019) use Habermas' theory of social interactions (Eriksen and Weigård 2003; Corchia 2013) to pinpoint three kinds of constraints of distinctive importance: framing, governance and initiative. The distinctive importance granted to these three constraints reflects 
Habermas's typology of 'models of action'. Habermas (1984) claims that the most important sociological and philosophical theories in the literature understand decision making based either on a "strategic model", a "norm-regulated model" or a "dramaturgic model". Habermas argues that all three models shed partial but relevant light on decision making, and Meinard \& Tsoukias (2019) introduce framing, governance and initiative as constraints determining the most relevant model to apply to a given situation (the strategic models is particularly relevant when framing is binding, norm-regulated when governance is binding, and dramaturgic when initiative is binding).

This typology of constraints, and its implications in terms of a discrepancy between proto- and constrained problem, can be easily translated in conservation contexts.

'Framing' refers to scientifically authoritative third-parties (formal or informal) monitoring $\mathrm{DM} / \mathrm{CB}$ interactions and imposing the methodologies that $\mathrm{CB}$ should use. Take, for example, the case of a DM who seeks decision support from a $\mathrm{CB}$ to elaborate a preservation action plan for a population of an endangered species. In cases where framing is dominant, the CB finds her/himself incapable of truly tackling the proto-problem 'what does conservation science teach us about how to carve out the preservation plan?' Indeed, because a scientific authoritative third party, such as a national or international expert agency or funding partner, imposes a specific methodology that the CB cannot question, she/he has no choice but to address the constrained problem 'what is the best preservation plan that can be produced using the imposed methodology?'

The governance constraint refers to requirements that decisions should be validated by some actors, such as a steering committee or an assembly of stakeholders. In our fictitious example, when this constraint is dominant, rather than addressing the proto-problem, the CB is forced to address the constrained problem "what kind of preservation plan will be acceptable to those 
people whose acceptance is key to its implementation?' In such cases, the job is to identify who those people are and which decisions reflect their legitimate expectations.

The initiative constraint characterizes situations where the most important outcome of the process is that the DM should endorse the final decision as its own. In our example, the constrained problem that the $\mathrm{CB}$ ends up addressing is no longer the proto-problem, but is closer to 'what kind of preservation plan will meet the DM's values and preferences?' The task is then to identify a decision which is as faithful as possible to the DM's values and preferences.

This model offers a plausible explanation for the existence of a discrepancy between the naïve view of $\mathrm{CB} / \mathrm{DM}$ interactions, and actual outcomes of such interactions. However, it remains purely theoretical, and leaves basic empirical questions unanswered. What kind of real-life situations correspond to those mentioned in the model? What are the real-life factors constituting the three constraints? What are the concrete implications for practitioners? Answering such empirical questions involves implementing the above framework by analysing concrete conservation decision processes.

\subsection{Operational implementation}

Here we outline the steps of such a practical implementation, specifying the sequence of questions that should be answered, based on consultations of the documents formalizing the decision process and/or on interviews with the actors involved.

- Step 1: Initial characterization of the decision process. The main prima facie features of the decision process should be identified by answering the following questions:

$\circ \mathrm{Q}^{\mathrm{pp}}$. What is the proto-problem allegedly addressed?

$\circ \mathrm{Q} 1^{\mathrm{DM}}$. Who is the DM? In other terms: which actor or institution claims to be in charge of the resolution of the proto-problem just identified? 
$\circ \mathrm{Q}^{\mathrm{CB}}$ : Who is or who are the $\mathrm{CB}$, i.e. who are the actors entrusted to close knowing-doing gaps in the case at hand? actors or institutions representing the framing, governance and initiative constraints, and to characterize the influence they can have on the decision process. This involves answering the following three questions:

$\circ 2^{f}$. Are there actors who impose a specific approach, methodology or theoretical framework to be used in the process?

Q $2^{\mathrm{g}}$ : What are the procedures used to validate or invalidate the decisions made by the DM? Who are the actors involved, and what are their prerogatives?

O Q2 $2^{\mathrm{i}}$. How important is it for the DM to endorse the responsibility for the decision and to conceive of it as his/her own decision?

- Step 3: Translation in terms of problem formulation. The proper characterization of constraints is then used to formulate the problem that the process truly tackles, due to the influence of the constraints preventing the DM from truly tacking the proto-problem (or allowing her/him not to tackle it) $\left(\mathrm{Q}^{\mathrm{cp}}\right)$.

- Step 4: Diachronic analysis. Most decision processes take time, and actors and procedures evolve over time. As a consequence, the constraints binding the process and the corresponding formulation of the problem addressed also evolve, yielding a 'refined problem'. The former three steps must hence be reiterated to get a dynamic picture of the decision process, clarifying these refined problems $\left(\mathrm{Q} 4^{\mathrm{rp}}\right)$.

To clarify the empirical bearings of this constraints analysis framework, following the abovedescribed steps, we analyzed a series of conservation decisions made inside and near the 
Northern Vosges Natural Park (North-east France), looking for decisions that would illustrate

146 how the three constraints above - governance, initiative, framework - materialize.

147 We explored three conservation decision processes, chosen because each one illustrates one of 148 the three constrains structuring our framework. In the thee decision processes, the Natural Park 149 of the Northern Vosges (hereafter, 'the Park') plays a pivotal role thanks to its official 150 attributions, spelled out in a territorial charter regularly revised by local authorities and 151 approved by the central government (the current version covers 2014-2025). Its main missions

are: protection and management of the local natural, cultural and landscape heritage, promotion of local actors' initiatives, ecological monitoring, environmental education, mediation on conservation issues, and coordination of conservation projects. The Park's charter also identifies key local actors and their commitments.

Data were collected through interviews with local stakeholders and analyses of available documentations. During an exploratory phase, we first observed the local context and led faceto-face interviews with stakeholders to identify the responsibilities and tasks of different actors. We then explored official reports and planning documents, relevant laws and regulations, institutional websites, communication flyers and newspapers, before performing a new series of more focused interviews with key actors (October 2019 to February 2020). This recursive process enabled us to answer the series of stepwise questions spelled out above.

\section{Results}

Here we present our case studies and the outcome of constraints analysis. We detail the four steps [paragraphs (1) to (4)] and provide answers to the corresponding questions in each case. The main actors and the constraints analyzed in each case studies are presented in Table 1. 
(1) Protecting and restoring biodiversity at a transboundary level is one of the Park's chief objectives, especially through its involvement in the Franco-German Palatinate Forest / Northern Vosges Biosphere Reserve. Reintroducing the lynx [Lynx lynx (Linnaeus, 1758)] in this Reserve is one of its most ambitious projects.

Early trials in 1983 and 1993 eventually failed in the early 2000s. High mortality initially plagued these programs, but a stable population could subsequently be secured for a while. The population then collapsed after 2005. In 2013, the lynx had practically disappeared again. The most credible cause was poaching.

During these first trials, the Park was in charge of piloting reintroduction, endorsing the role of the DM $\left(\mathrm{Q} 1^{\mathrm{DM}}\right)$. Members of the scientific committee of the Park, consultants, as well as researchers and team leaders from other simultaneous programs in Switzerland, Germany and Italy $\left(\mathrm{Q} 1^{\mathrm{CB}}\right)$ were solicited to help address the problem 'how to reintroduce a stable population of lynx?' $\left(\mathrm{Q} 1^{\mathrm{pb}}\right)$

(2) But the dramatic collapse in the 2000s' testifies to the decision process having been bound by constraints that were insufficiently taken into account at that time, and that the problem the Park used to conceive of itself as tackling was a hollow proto-problem. These constraints were the following. The Park participated in releases, but had no influence on their design. Its ability to skew the process to make it fit with its own understanding or objectives, which is what we have defined above as an initiative constraint, was hence weak $\left(\mathrm{Q} 2^{\mathrm{i}}\right)$. The design of the process did not involve any overarching authority liable to constrain the methodological approaches that the above CB could use. The framework constraint was hence non-existent $\left(\mathrm{Q}^{\mathrm{f}}\right)$. By contrast, the stakeholders concerned were numerous, including hunters, farmers, inhabitants, local authorities and forest managers. Most of them were, and still are, 
well organized in NGOs or federations, regularly invited into meetings through which they could voice their opposition to reintroduction, and put pressure on local elected representatives to undermine the project. Indeed, although the lynx does not create any major risks for human beings (Wyver 2014), stances toward the lynx are cleaving (as witnessed in most carnivores reintroductions; Tokarski, 2019). These various actors hence proved to have an unexpected ability to validate or invalidate the DM's choice, which constitutes a governance constraint which was, and still is, accordingly tightly binding $\left(\mathrm{Q}^{\mathrm{g}}\right)$.

(3) Acknowledging the importance of this constraint progressively led the Park to understand that taking into account perceptions and human behavioral responses is key to successful reintroductions (Tokarski, 2019). The Park had to accept that it could not tackle the proto-problem 'how to reintroduce a stable population of lynx?', and progressively refocused towards a constrained problem it was able to tackle: 'how to increase the acceptability of the lynx?' (Q3 $\left.{ }^{\text {cp }}\right)$ The current Life+ Lynx project (2016-2021; https://www.lifelynx.eu/) drew lessons from this experience: the Park now endorses the aim to enhance social acceptability. Having conducted a sociological study, it currently runs environmental education programs and has launched a participatory process, the 'Lynx Parliament', facilitated by independent experts, in which it is involved on a par with farmers, hunters, inhabitants and local authorities.

The Park hence followed a path through which it unwittingly analyzed constraints and, based on this, managed to clarify a constrained problem it was truly able to tackle. This eventually enabled it to act more decisively, by focusing on actions it was able to perform, rather than wasting time, money and energy on actions devoted to tackle a proto-problem in which it was doomed to be impotent.

(4) Interesting evolutions of the lynx parliament occurred lately. Whereas its first phase focused on information and communication (deployment of information-sharing tools and alert procedures based on mutual commitments), a second phase organized discussions among users 
to share experiences and expertise regarding attitudes towards the lynx. The decision setting hence evolved, from stages during which acceptance or rejection by stakeholders was considered untouchable, to approaches through which the legitimacy of these attitudes started to be questioned, and stakeholders began to conceive of themselves as actors liable to make new commitments. Such evolutions go in the direction of mitigating the governance constraint, which could eventually lead to restructuring the decision setting towards tackling a refined problem such as 'How to integrate lynx reintroduction within local development paths?' (Q4 ${ }^{\mathrm{rp}}$ ) Solving such a problem could be a much more meaningful contribution to local conservation.

\subsection{Water quality monitoring - a decision process mainly constrained by framework}

(1) The current charter of the Park stresses the importance of the issue of surface water quality, in part due to its position at the head of numerous watersheds. This concern echoes the broader context in the Rhine-Meuse basin, where more than half the watersheds have had to postpone to 2021 or even 2027 the European objective to reach a good ecological status (Charter of the Park, 2014, p. 26). Tackling the problem 'how local water quality can be monitored and improved?' $\left(\mathrm{Q}^{\mathrm{pb}}\right)$ is hence at the top of the Park's agenda.

The Park launched in 2012 a monitoring program, the 'river water quality observatory', for which it endorsed, along with local public representatives legally in charge of local water quality monitoring, the role of $\mathrm{DM}\left(\mathrm{Q} 1^{\mathrm{DM}}\right)$. To design the network of monitoring stations, perform measures and interpret the results, the Program Officer in charge of river and water issues consulted specialists in the scientific committee and hired various consultants as part of public procurement procedures $\left(\mathrm{Q}^{\mathrm{CB}}\right)$.

(2) The Park coordinated institutional partners such as local authorities, and funding actors supporting the cost of measurements and analyses involved, such as the Water Agency 
(overseeing the implementation of the European Water Framework Directive [2000/60/CE; https://ec.europa.eu/environment/water/water-framework/index_en.html]). In this process, the Park did not wield a significant initiative constraint, in the sense that it mainly trusted the competence of other actors to make cogent choices of tools and approaches. The various actors involved did not play a decisive role in validating or invalidating decisions made by the DM: in that sense, the process was not constrained by a tight governance constraint $\left(\mathrm{Q}^{\mathrm{g}}\right)$. However, among these actors, the Water Agency exerted another tight constraint: framing $\left(\mathrm{Q} 2^{\mathrm{f}}\right)$. Indeed, water agencies are responsible for regional-scale programs and policies, buttressed on monitoring schemes using standardized indicators, summary statistics and a technical and scientific framework to analyze and interpret these data. The Water Agency brought in this technical and scientific apparatus, which was chosen as self-evidently relevant.

(3) Being ensconced in the framework of the Water Agency, far from addressing the protoproblem 'what is the quality of local water?' the Park ended up addressing the much more specific, constrained problem 'How does local water quality fare with respect to European water quality criteria?' $\left(\mathrm{Q}^{\mathrm{cp}}\right)$

(4) Launched in 2015, the observatory has been fully operational since 2018, addressing the constrained problem through the application of usual indicators to 31 reporting stations. It unveiled that local water quality scores were not as good as expected. These results led some local actors to dig deeper, as they became aware that the process only provided a partial answer to their original, broader concern. Underlying causes were investigated. Ancient mines, sewerage conditions in small isolated villages and insufficient protection of wetlands were 263 pinpointed. This prompted a collective rethinking of the relevance of the framework. The decision process hence evolved towards addressing the refined problem 'what are the relevant criteria to capture the water quality regarding local situation and concerns?' $\left(\mathrm{Q}^{\mathrm{rp}}\right)$ and the 
Water Agency rallied to the new approach by maintaining its financial support in its current program (2019-2024).

\subsection{Aquatic ecosystem management and fish stock protection - a decision process} mainly constrained by initiative

(1) In the Lower Rhine, the fragmentation of aquatic ecosystems is of particular concern (Charter of the Park, 2014, p. 29). Anglers play a key role in the management of aquatic ecosystems. Associations Agréées pour la Pêche et la Protection du Milieu Aquatique (Accredited Associations for Fishing and for the Protection of the Aquatic Environment; AAPPMA) are in charge of regulating, monitoring and promoting angling. These AAPPMAs are associated at the departmental level in a Federation (Fédération de Pêche du Bas-Rhin, no date) whose actions are organized by a Plan Départemental de Protection du milieu aquatique et de Gestion des resources piscicoles (Departemental Blueprint for the protection of aquatic ecosystem and the Management of Fish stocks, PDPG), for the elaboration and implementation of which, as DM $\left(\mathrm{Q} 1^{\mathrm{DM}}\right)$, they hired conservation consultancies and benefited from informal discussions with researchers $\left(\mathrm{Q} 1^{\mathrm{CB}}\right)$. At first sight, it looks as though local fishing associations implementing actions as applications of the PDPG address the problem 'How to preserve the ecological functioning of aquatic ecosystems and fish stocks?' (Q1 $\left.{ }^{\mathrm{pp}}\right)$

(2) AAPMAs typically solicit technical and scientific advice from program officers and experts on specific projects when needed. However, despite the existence of monitoring frameworks and recommendations promoted by various actors (including calls for rewilding streams [Brown et al., 2018; Hawley, 2011]), they are by and large unconstrained in their choice of a theoretical or scientific framework to address ecological functioning and connectivity $\left(\mathrm{Q}^{\mathrm{f}}\right)$. The ability of other stakeholders to constrain the anglers' approach is weak. Water agencies, NGOs, and political representatives are sometimes involved in decision processes 
291

piloted by anglers, but their role remains mainly consultative: there is no formal or informal procedure through which these actors could validate or invalidate the DM's choices. The governance constraint hence also appears limited $\left(\mathrm{Q}^{\mathrm{g}}\right)$.

The ability of institutions and representatives of fishermen to pilot the monitoring and management of aquatic ecosystems is hence unchallenged $\left(\mathrm{Q} 2^{\mathrm{i}}\right)$.

(3) In this context, the initiative constraint takes the upper hand, and fishermen do not really address the proto-problem 'how to preserve ecological functioning and fish stock?' but rather the constrained problem 'how to make sure that the fish stocks we want are available in fishing spots?' $\left(\mathrm{Q} 3^{\mathrm{cp}}\right)$

(4) Because it witnessed in nearby watersheds the mismatch between ecological concerns underlined by the proto-problem and the fairly limited constrained problem addressed by anglers, the Park recently attempted to improve the way issues of ecological continuity are handled within its perimeter. It solicited 29 organizations representing fishermen to join a program devoted to preserving aquatic ecosystems. Fishermen were invited to share their knowledge and concerns, and they can benefit from technical training and mutual learning (Charter of the Park, 2014 p.33). In this setting, fishermen no longer enjoy any vantage role, which deprives them of the ability to wield a tightly binding initiative constraint, and the constrained problem is here replaced by the refined problem 'How to improve aquatic ecosystem management and local fish stock preservation?' (Q4P). As a result, up to $12 \mathrm{~km}$ of rivers have already been restored since 2012, under the leadership of the Park and thanks to the voluntary commitment of fishermen. Scientific collaborations including the Park, AAPPMAs and biologists were also launched in 2019 as part of the ECOSERV INTERREG project.

\section{Discussion}


The above applications of constraints analysis offer retrospective insights into reasons why some conservation projects were successful while others failed, or explaining why some projects changed their objectives or approaches over time. Even though, in these cases, there was no single $\mathrm{CB}$ who interacted with the $\mathrm{DM}$, but rather a moving series of actors and consultants (as is often the case), such retrospective insights are useful for CBs concerned to bridge knowing-doing gaps, because they help understanding of the complexity of decision processes in general. However, beyond such ex post analyses, the four steps constituting constraints analysis can also be followed by CBs as a way to rationalize their interactions with DMs as they unfold. Here we discuss the prospects and limits of constraints analysis, with this idea of possible future performative applications in mind.

\subsection{Promises of constraints analysis}

Numerous tools have been recently introduced to improve conservation decision making by acknowledging that social sciences are 'a vital component, along with the natural sciences, for effective conservation decision-making' (Bennett et al. 2017). These tools can be classified as (Bower et al. 2018): 1) tools that help selecting, comparing and cumulating decision criteria to identify optimal decisions when the context is not plagued by problematic uncertainties; 2) tools designed to address more uncertain contexts, such as Structured Decision Making (Gregory et al., 2012) or other stepwise frameworks (Schwartz et al., 2018). Deliberative and participatory processes and other devices of collective intelligence (Vercammen \& Burgman, 2019) also belong to this second category. Making cogent choices among these tools presupposes a clear understanding of the problem addressed by the decision process. By unveiling major discrepancies between proto-, constrained and refined problems in our three case-studies, our results illustrate that this prerequisite is far from being trivial. 
In this respect, our results echo the abundant literature emphasizing that framing a clear and solvable problem is an essential step (Hoppe \& Hisschemöller, 2001; Bower et al., 2018) the importance and challenges of which are often underestimated (Gregory et al., 2012; Groves \& Game, 2016). Many prioritization schemes collapse at this stage (Game et al. 2013). The complexity involved mainly stems from the importance of acceptability to the public (Rose et al., 2018) and the institutional context (Ostrom, 1990; Engen \& Hausner, 2018). Value or decision trees, influence diagrams (Bower et al., 2018), and companion modelling (Barreteau et al., 2003) are standard approaches to support problem definition. Constraints analysis is complementary to these approaches, by clarifying the dimensions of the situation (actors, institutions, rules and patterns of behaviour constituting the initiative, governance and framework constraints) that should be analysed and taken into account when defining the problem. Had the above approaches been implemented in our case studies, a prior constraints analysis along the lines spelled out in Results would have facilitated their proceedings.

Cases where the governance constraint is binding are of particular interest in this respect. In such cases, as illustrated in our lynx reintroduction case study, problem definition is plagued by a form of complexity and uncertainty that stems from the diversity of points of view represented in bodies and people constituting the governance body (possibly along with other forms of uncertainty). Taking this uncertainty into account is pivotal to make relevant choices of tools (Bower et al., 2018). This can be done through the use of processes and decision tools, which will enable the $\mathrm{DM}$ and $\mathrm{CB}$ to ensure that they capture all the relevant points of view when identifying the constrained problem and, eventually, when refining it. Depending on the situation and, in particular, on conflicts that could emerge, deliberative/participative tools designed to prevent minority tyranny (López-Bao et al., 2017), deliberative multi-criteria analysis (Davies et al., 2013; Baynham-Herd et al., 2020; Redpath et al., 2004), Structured Decision Making (Gregory et al., 2012), collaborative decision analytics (Mattsson et al., 2019) 
can prove relevant. When using such deliberative/participative tools, constraints analysis can provide guidance to check if the conditions for meaningful co-production (Turnhout \& Van Bommel, 2010; Turnhout et al., 2020) are fulfilled. Indeed, among the factors undermining these conditions, power imbalances are problematic when they participate in skewing a binding governance constraint. Analysing this constraint is hence instrumental to identifying power imbalances and to determining how problematic they are. Similarly, depoliticization, another phenomenon undermining co-production, can materialize as a skewed governance or framework. By highlighting distortions in governance or framework, constraints analysis can hence be instrumental in unveiling depolitization. Because the arbitrariness and hidden valuejudgments that can stem from defective deliberative and participative processes are acknowledged to be major problems plaguing conservation action (Game et al. 2013), constraints analysis can thereby usefully contribute to improving conservation.

Clarifying constrained problems can also contribute to enhancing dialogues by homogenising vocabulary (Wilhelm-Rechmann and Cowling 2011), as illustrated by the construction of the common document of mutual commitment as an output of the 'Lynx parliament'. It can also help better identify or facilitate the expression of the DM's needs and expectations (Matzek et al. 2015; Toomey et al. 2017), as illustrated in the water quality casestudy. Constraints analysis also holds promise for strengthening two key aspects of conservation actions: their legitimacy and their ambition.

The legitimacy of decisions is increasingly acknowledged to be key to effectiveness in conservation (Yanco et al., 2019) and beyond (Meinard \& Tsoukiàs, 2019). If decisions are not legitimate, DMs will have difficulties finding resources to implement them and stakeholders may refuse to comply with new rules, as witnessed in the first stages of the lynx case-study. The analysis of decision processes through the path from proto- to constrained problem can be instrumental in legitimizing conservation action. By understanding and addressing the right 
constrained problem, CBs improve their ability to legitimize their actions by placing themselves in a position to account for them and explain them transparently. The evolution of the Park's approach and its perception by stakeholders in the lynx case study illustrate this legitimization process.

Because constrained problems are often limited in scope and lack scientific interest, clarifying them can also usefully highlight the need to address more ambitious (in the sense of being scientifically challenging and having wide-range consequences) problems, and motivate DMs, stakeholders and/or CBs to undertake specific actions and mobilise relevant tools to mitigate constraints binding decision processes, so as to be able to address such problems. In such attempts to upgrade the ambition of conservation actions, an important aspect to consider is the extent to which they address systemic links within socio-ecosystems, since this is a precondition to bring global ecological and socioeconomic benefits in the long run (Wilson et al. 2016, Larrosa et al. 2019). This potential to upgrade the ambition of conservation initiatives is illustrated by the recent initiative to strengthen ecological connectivity through information sharing and technical cooperation, in our third case study.

By enabling the development of more ambitious conservation actions, constraints analysis can hence play an important role in fulfilling the promise of conservation social sciences, not only to improve conservation decision effectiveness (Bennett et al., 2017), but also to leverage conservation transformative power through behavioural change (Bennett \& Roth, 2019). Striving to mitigate constraints in such attempts to strengthen conservation actions may be costly and uncertain, and these costs should certainly be considered in a decision assessment (Pannell \& Gibson, 2016). But the status quo can also be costly, especially when public engagement is pivotal. 
414

The three case studies above concerned situations where a single constraint plays a conspicuous role. Many situations will be more complicated, with two or more constraints acting simultaneously. Besides, in some situations, the $\mathrm{CB}$ who provides decision support can herself or himself be nested in another decision interaction where s/he is provided support by someone else. Very complex nested structures can hence exist, and they call for much more sophisticated analyses than those developed in the present case studies. Future studies exploring our framework should be devoted to such complex situations.

The challenges involved in implementing constraints analysis as a performative tool rather than as post hoc analytical tools should also not be underestimated, and call for dedicated future studies. In any case, the application of constraints analysis depends largely on the ability of CBs and DMs to observe and analyse initiative, governance, and framework constraints. It also presupposes that they are not driven by arbitrary judgements and personal interests; our reasoning abstracts from the obvious fact that real-life conservation biologists are not pure representatives of sciences, but rather individuals, with their own interests, constraints, and agendas. Constraints analysis engages researchers' intuition and creativity as well as their analytical skills and allows them to play an active role throughout the process. Although some clues have been given in this article to help diagnosis, our intention was not to delve into the details of how constraints analysis can be deployed in all kind of situations, but to demonstrate its usefulness at a general level. In particular, the last part of each of our case studies illustrates, in broad outline, how CBs can strive to mitigate constraints to clarify and tackle a refined problem that is more meaningful, from a conservation point of view, than the constrained problem to which they are confined if they simply accept existing constraints. 
However, mitigating constraints is a challenging task. In general terms, mitigating the framework constraint involves questioning the validity of theories, protocols and methods encapsulated in the framework, mitigating the governance constraint consists in questioning the legitimacy of the members of the governance, and mitigating the initiative constraint means questioning the importance granted to the requirement that the DM should see the decision as its own. But beyond these very simple ideas, future studies are needed to clarify methods and techniques to develop successful interventions to mitigate constraints in practice.

Based on the reasoning developed here, we claim that constraints analysis can contribute to bridging knowing-doing gaps in conservation and to strengthening the legitimacy and ambition of conservation actions. That said, we do not claim that constraints analysis alone will be enough to solve all the problems associated with the current biodiversity crisis. New, more efficient strategies to influence decision making and mobilise political support for conservation (Johns, 2019) and broad cultural changes such as that promoted by Buscher \& Fletcher (2019) have an irreducible role to play.

\section{References}

Arlettaz R, Mathevet R (2010) Biodiversity conservation: from research to action. Natures Sciences Societes 18: 452-458.

Barreteau O, Antona M, D’Aquino P, Aubert S, Boissau S, Bousquet F, Daré W et al. (2003) Our companion modelling approach. Journal of Artificial Societies and Social Simulation 6:1.

Baynham-Herd Z, Redpath S, Bunnefeld N, Keane A (2020) Predicting intervention priorities for wildlife conflicts. Conservation Biology 34: 232-243. 
Beier P, Hansen LJ, Helbrecht L, Behar D (2017) A How-to Guide for Coproduction of Actionable Science. Conservation Letters 10: 288-296.

Bennett NJ, Roth R (2019) Realizing the transformative potential of conservation through the social sciences, arts and humanities. Biological Conservation 229: A6-A8.

Bennett NJ, Roth R, Klain SC, Chan K, Christie P, Clark DA, Cullman G, et al. (2017) Conservation social science: Understanding and integrating human dimensions to improve conservation. Biological Conservation 205: 93-108.

Biggs D, Abel N, Knight AT, Leitch A, Langston A, Ban NC (2011) The implementation crisis in conservation planning: could 'mental models' help? Conservation Letters 4: 169-183.

Bower SD, Brownscombe JW, Birnie-Gauvin K, Ford MI, Moraga AD, Pusiak RJP, Turenne ED et al. (2018) Making Tough Choices: Picking the Appropriate Conservation Decision-Making Tool. Conservation Letters 11: e12418.

Brown AG, Lespez L, Sear DA, Macaire JJ, Houben P, Klimek K, Brazier RE et al. (2018) Natural vs anthropogenic streams in Europe: history, ecology and implications for restoration, river-rewilding and riverine ecosystem services. Earth-science reviews 180: 185-205.

Charter of the Northern Vosges Natural Park (2014) Projet de territoire Horizon 2025, Charte du Parc naturel régional des Vosges du Nord, 138p. https://www.parc-vosges-nord.fr/wpcontent/themes/adipso/_images/charte.pdf.

Corchia L (2013) Jürgen Habermas. A bibliography: Works and studies (1952-2013): With an introduction by Stefan Müller-Doohm. Arnus Edizioni-Il Campano. 
Davies AL, Bryce R, Redpath SM (2013) Use of Multicriteria Decision Analysis to Address Conservation Conflicts: Multicriteria Decision Analysis. Conservation Biology 27: 936-944.

Engen S, Hausner VH (2018) Impact of Local Empowerment on Conservation Practices in a Highly Developed Country. Conservation Letters 11: 1-8.

Eriksen EO, Weigård J (2003) Understanding Habermas Communicative Action and Deliberative Democracy. London: Continuum, 292p.

Fédération de Pêche du Bas-Rhin (no date). https://www.peche67.fr/ Accessed 19 April 2021.

Ferraro PJ, Pattanayak SK (2006) Money for Nothing? A Call for Empirical Evaluation of Biodiversity Conservation Investments. PLOS Biology 4: e105.

Game ET, Kareiva P, Possingham HP (2013) Six Common Mistakes in Conservation Priority Setting: Priority-Setting Mistakes. Conservation Biology 27: 480-485.

Game ET, Schwartz MW, Knight AT (2015) Policy Relevant Conservation Science. Conservation Letters 8: 309-311.

Gregory R, Failing L, Harstone M, Long G, McDaniels T, Ohlson D (2012) Structured decision making: a practical guide to environmental management choices. WileyBlackwell, 312p.

Groves C, Game ET (2016) Conservation planning: informed decisions for a healthier planet. Roberts Publishers, 608p.

Habermas J (1984) Theory of Communicative Action, Volume One. Boston: Beacon Press. 
Hawley S (2011) Recovering a lost river: Removing dams, rewilding salmon, revitalizing communities. Boston: Beacon Press, 256p.

Hoppe R, Hisschemöller M (2001) Coping with intractable controversies: the case for problem structuring in policy design and analysis. In: Knowledge, Power and Participation in Environmental Policy Analysis, pp. 42-72. London: Transaction Publisher.

Jarić I, Quétier F, Meinard Y(2019) Procrustean beds and empty boxes: On the magic of creating environmental data. Biological Conservation 237: 248-252.

Johns D (2019) Conservation politics: the last anti-colonial battle. Cambridge University Press.

Knight AT, Cowling RM, Rouget M, Balmford A, Lombard AT, Campbell BM (2008) Knowing but not doing: selecting priority conservation areas and the researchimplementation gap. Conservation biology 22: 610-617.

Larrosa C, Carrasco LR, Tambosi LR, Banks-Leite C, Milner-Gulland EJ (2019) Spatial conservation planning with ecological and economic feedback effects. Biological Conservation 237: 308-316.

López-Bao JV, Chapron G, Treves A (2017) The Achilles heel of participatory conservation. Biological Conservation 212: 139-143.

Mattsson BJ, Arih A, Heurich M, Santi S, Štemberk J, Vacik H (2019) Evaluating a collaborative decision-analytic approach to inform conservation decision-making in transboundary regions. Land Use Policy 83: 282-296. 
Matzek V, Pujalet M, Cresci S (2015) What Managers Want From Invasive Species Research Versus What They Get. Conservation Letters 8: 33-40.

Meinard Y, Tsoukiàs A (2019) On the rationality of decision aiding processes. European Journal of Operational Research 273: 1074-1084.

Ostrom E. (1990) Governing the commons: the evolution of institutions for collective action. Cambridge University Press.

Pannell DJ, Gibson FL (2016) Environmental cost of using poor decision metrics to prioritize environmental projects: Cost of Poor Decision Metrics. Conservation Biology 30: $382-391$.

Redpath SM, Arroyo BE, Leckie FM, Bacon P, Bayfield N, Gutierrez RJ, Thirgood SJ (2004) Using Decision Modeling with Stakeholders to Reduce Human-Wildlife Conflict: a Raptor-Grouse Case Study. Conservation Biology 18: 350-359.

Rose DC, Sutherland WJ, Amano T, González-Varo JP, Robertson RJ, Simmons BI, Wauchope HS et al. (2018) The major barriers to evidence-informed conservation policy and possible solutions. Conservation Letters 11: e12564.

Schwartz MW, Cook CN, Pressey RL, Pullin AS, Runge MC, Salafsky N, Sutherland WJ et al. (2018) Decision Support Frameworks and Tools for Conservation. Conservation Letters 11: e12385.

Sunderland T, Sunderland-Groves J, Shanley P, Campbell B (2009) Bridging the gap: how can information access and exchange between conservation biologists and field practitioners be improved for better conservation outcomes? Biotropica 41: 549-554. 
544 Sutherland WJ, Pullin AS, Dolman PM, Knight TM (2004) The need for evidence-based conservation. Trends in Ecology \& Evolution 19: 305-308.

Tokarski M (2019) Hermeneutics of Human-Animal Relations in the Wake of Rewilding. Springer.

Toomey AH, Knight AT, Barlow J (2017) Navigating the Space between Research and Implementation in Conservation. Conservation Letters 10: 619-625.

Tsoukiàs A (2007) On the concept of decision aiding process: an operational perspective. Annals of Operations Research 154: 3-27.

Turnhout E, Metze T, Wyborn C, Klenk N, Louder E (2020) The politics of co-production: participation, power, and transformation. Current Opinion in Environmental

Turnhout E, Van Bommel S (2010) How participation creates citizens: participatory governance as performative practice. Ecology and Society 15: 26.

Vercammen A, Burgman M (2019) Untapped potential of collective intelligence in conservation and environmental decision making. Conservation Biology 33: $1247-$

Wilhelm-Rechmann A, Cowling RM (2011) Framing biodiversity conservation for decision

Wilson RS, Hardisty DJ, Epanchin-Niell RS, Runge MC, Cottingham KL, Urban D L, Maguire LA et al. (2016) A typology of time-scale mismatches and behavioral 
interventions to diagnose and solve conservation problems: Time-Scale Mismatches. Conservation Biology 30: 42-49.

567

568

569

570

571

Wyver J (2014) The Lynx Effect. Thesis submitted for the Master of Science in Conservation Science and the Diploma of Imperial College London. Supervised by: Murray Collins, Paul De Ornellas and Marcus Rowcliffe.

Yanco E, Nelson MP, Ramp D (2019) Cautioning against overemphasis of normative constructs in conservation decision making. Conservation Biology 33: 1002-1013. 